used for collecting particles is far too elaborate and heavy for extensive use in this fashion. This difficulty has been overcome by merely allowing the particles to impact naturally on adhesive cylinders held into the wind by light vanes spaced out along the balloon cable. Spores of Lycopodium are used as these are big enough (30 micron diameter) to impart with reasonable efficiency (near 50 per cent in normal wind speeds for a cylinder of diameter 0.25 in.), relatively easy to recognize and count under a microscope of moderate magnification, and yet possess a free falling velocity $(2 \mathrm{~cm}$./ $/ \mathrm{sec}$.) which will normally be much less than one-tenth of the vertical eddy velocities.

A first series of experiments has been carried out using the above technique, the particles being released for half an hour at a time at a height of $500 \mathrm{ft}$. and sampled at distances of a few hundred yards downwind. At the same time the fluctuating inclination of the wind at the position of release of the particles was measured by a light responsive vane, the movements of which were recorded electrically at groundlevel. This instrument was designed especially for use on a balloon cable and includes automatic compensation for the varying inclination of the cable. The few results analysed so far indicate that even after a travel of 500 metres, the vertical distribution of particles may still be very closely in accordance with the distribution of the inclination of the wind. This implies the existence of a Lagrangian type of correlation, that is, one which is concerned with the velocities of the same sample of air at successive intervals of time, with a coefficient maintained close to unity for as long as one minute or more. On the other hand, from the 'instantaneous' values of wind inclination, it was found that the Eulerian cor- relation coefficient, namely, that between the inclination at a fixed point at a given time and the inclination at the same point some time later, had fallen to near zero in about $10 \mathrm{sec}$. This much greater persistence of velocity in a Lagrangian than in a Eulerian sense is a known feature of wind-tunnel turbulence, and evidence is now accumulating for a similar feature in atmospheric turbulence. If it is confirmed, this would mean that the convenient substitution of the measurable Eulerian coefficient for the almost unmeasurable Lagrangian coefficient is unacceptable even as a rough approximation. How. ever, experiments of the present type may then reveal systematic connexions between the Lagrangian and Eulerian characteristics, as in fact has already been done in wind-tunnel experiments, and so provide some real physical insight into the fundamental features of atmospheric diffusion.

In addition to studying the relation between diffusion and the measurable aspects of eddy structure, it will also be important to have a more general description of the space-time variations of eddy structure than is available from the conventional micrometeorological investigations near the surface. The instrument for measuring the fluctuations of wind inclination from a mounting on a balloon cable has already been operated with some success at heights up to $5,000 \mathrm{ft}$. and has provided some interesting indications of the variations of turbulence with height and time. Plans are now in hand to increase the instrumental equipment and to use it more extensively. Such measurements should provide further knowledge of the nature, growth and decay of mechanical turbulence and convective motion over a substantial depth of the troposphere.

\title{
REVISION OF THE POLICY ON BREAD IN GREAT BRITAIN
}

$\mathrm{T}$ OWARDS the end of the Second World War, consideration was given in Britain to the desirability of specifying the type of flour to be used for bread-making once the period of war-time restrictions was over. The Conference on the Post-War Loaf ${ }^{1}$ recommended that an 80 per cent extractionlevel should be the minimum permitted and that more refined flours enriched with two or three nutrients should not be considered equally acceptable. A report by the panel on Composition and Nutritive Value of Flour has now been published* which, while agreeing that a plain flour of less than 80 per cent extraction would constitute a nutritional hazard, nevertheless concludes that the addition of thiamine, nicotinic acid and iron would provide sufficient safeguard. This is the point of view favoured by the millers, and it was chiefly pressure from them that caused the present Panel to be set up.

When, in 1953, the Government found it possible to relax controls on cereals, the trade obtained permission to prepare flour of 70 per cent extraction provided thiamine, nicotinic acid and iron were added to it ; but such flour did not qualify for subsidy when used in bread-making. To the surprise of the millers, the public showed remarkably little interest in this new flour, and sales of bread made from it

* Report of the Panel on Composition and Nutritive Value of never reached a higher proportion than 4.4 per cent of total bread sales; by the middle of 1955 this proportion had dropped to 0.8 per cent. The millers claim that the public really prefers such bread but cannot afford to buy it. It would seem equally arguable that people were quite satisfied with the National loaf.

In pressing for permission to mill a low-extraction flour, the millers also sought (and obtained) permission to make up National flour by blending as well as by the straight-run process. This completely undermined the safeguards which the Conference on the Post-War Loaf sought to provide, and the value of National flour steadily deteriorated. The present report refers to "the acknowledged infringement of the spirit of the Flour Order" and states that "The Panel believes that the immediate drop in the vitamin $B_{1}$ and nicotinic acid content of National flour after decontrol and the continuing fall since, have resulted primarily from deliberate disregard of the intention of the Flour Order rather than from such factors as variations in the character of the wheat from which the flour was milled, although these factors may have played a secondary role". The report argues that a policy of adding specified nutrients would give greater assurance of their presence, since "if the miller is free to sell enriched white flour of any technical quality which he desired 
Table 1. NUtRIENTS PRESENT IN WhEAT FLOUR (REPRESENTATIVE VALUES)

\begin{tabular}{|l|c|c|}
\hline Nutrients (per 100 gm. flour) & Wholemeal & $\begin{array}{c}\text { Flour of } \\
70 \text { per cent } \\
\text { extraction }\end{array}$ \\
\hline Proteins (gm.) & $12 \cdot 2$ & $11 \cdot 0$ \\
Fat (gm.) & $2 \cdot 3$ & $1 \cdot 1$ \\
Calcium (mgm.) & 45 & 18 \\
Potassium (mgm.) & 376 & 144 \\
Magnesium (mgm.) & 127 & 24 \\
Phosphorus (mgm.) & 287 & 102 \\
Sulphur (mgm.) & 165 & 108 \\
Chlorine (mgm.) & 62 & 53 \\
Tron (mgm.) & $4 \cdot 2$ & $0 \cdot 8$ \\
Copper (mgm.) & $0 \cdot 8$ & $0 \cdot 2$ \\
Manganese (mgm.) & $4 \cdot 5$ & $0 \cdot 4$ \\
Thiamianine ( $\mu$ gmm.) & 910 & 30 \\
Riboflavin ( $\mu \mathrm{gm})$. & 500 & 70 \\
Pyridoxine ( $\mu \mathrm{gm})$. & 100 & 35 \\
Choline (mgm.) & 460 & 220 \\
Folic acid ( $\mu \mathrm{gm})$. & 90 & 50 \\
Biotin ( $\mu$ gm.) & 50 & 12 \\
Nicotinic acid (mgm.) & 8 & $0 \cdot 5$ \\
Pantothenic acid (mgm.) & $7 \cdot 3$ & $1 \cdot 2$ \\
\hline
\end{tabular}

A full set of values is not available for flour of 80 per cent extraction but in general the higher the extraction-rate the greater the retention

there would not appear to be much temptation to add less than the specified quantities of nutrients".

The recommendations of the Conference on the Post-War Loaf, however, were intended to safeguard health by assuring that the flour used for breadmaking contained not only thiamine, nicotinic acid and iron, but also a fair measure of the numerous other nutrients which wheat can supply. Since exact requirements for many of these other nutrients have not yet been established, it cannot be said for certain that the differences between 80 per cent flour and enriched 70 per cent would prove of nutritional significance, but equally it cannot be said that they would not. The matter still awaits investigation (the so-called 70 per cent extraction flour used in the much discussed Widdowson and McCance experiments ${ }^{2}$ contained thiamine, riboflavin and nicotinic acid in quantities greater than is usual at that level and must be assumed to have provided more of the remaining nutrients also). Table 1 sets out some of the nutrients which are present in wheat and shows what a severe reduction occurs in milling to a 70 per cent extraction level. Only a few of these nutrients were given consideration by the Panel, yet the others may be of equal-or even greater-importance.

In this report the Panel gives the warning that "The history of nutrition reveals many instances where the refinement or over-purification of food has led to ill-health and there is no reason to believe that this chapter of knowledge is closed". The Panel, however, seems to assume that the National Food Survey would give adequate warning of any need for further revision of bread policy. But research workers already feel ${ }^{3}$ that over-sophistication of food may provide the explanation of many of the diseases which beset 'civilized' man despite his extensive medical services, and the present time seems inauspicious for a reduction of the dietary supply of some fifteen or more minor nutrients merely to suit trade interests. Moreover, the proposed change would require nearly a quarter of a million extra tons of wheat a year.

M. W. Grant

1 Rep. Conf. Post-War Loaf. (Cmd. 6701.) (London : H.M.S.O., 1945.)

2.Widdowson, E. M., and MeCance, R. A., Med. Res. Counc. Spec. Rep., Ser. 287. (London: H.M.S.O., 1954.)

${ }^{3}$ Platt, B. S., Brit. Med. J., i, 179 (1955). 'Sinclair, H. M., Lancet, i, 381 (1956).

\section{NATIONAL PHYSICAL LABORATORY}

\section{OPEN DAY}

$\mathrm{O}^{\mathrm{n}}$ PEN Day' at the National Physical Laboratory, Teddington, serves a dual function: it gives representatives of industry, universities, government departments and the technical and daily Press an insight into the work of one of the largest national research laboratories in Britain and, no less useful, serves to indicate the direction of national research effort in many branches of science and engineering. About three thousand visitors attended this year and 225 exhibits were on view. During the afternoon, the General Board of the Laboratory met to consider the Executive Committee's annual report ${ }^{1}$.

The Metallurgy Division celebrates this year its fiftieth anniversary, and it was appropriate that its exhibits provided evidence of its continued interest in the constitution and structure of metals and alloys in relation to their physical and mechanical properties, work for which the Division has gained an international reputation. An investigation of the constitution of a uranium-palladium system undertaken for the Atomic Energy Research Establishment revealed the interesting feature of a considerable solid solubility of uranium in palladium; since the electronic structure of palladium is known, measurement of certain physical properties such as electrical resistivity, paramagnefic susceptibility, thermoelectric power and lattice parameter suggested that uranium dissolves in dilute solution with an effective valency of 6 , but at higher concentrations the valency is probably 4.

The study of high-purity iron with particular reference to elucidating the embrittling effect of traces of impurities in amounts as low as 0.001 per cent has led to the development of an electrolytic process with the view of producing sulphur-free iron ; a commercial cation exchange membrane was used for dividing the electrolytic cell and preventing the transfer of the sulphur-containing anions. Tensile tests on single crystals of iron at $-196^{\circ} \mathrm{C}$. indicated that orientation had a marked effect on brittle fracture $^{2}$, and further investigations of rolled Swedish iron bar using the National Physical Laboratory X-ray diffractometer confirmed that texture had a marked effect on brittle properties. The tracer laboratory is now in full operation, and equipment has been designed to measure the rate of diffusion of antimony in copper, and to study the self-diffusion of silver under fatigue stress.

The steadily increasing use of radioactive materials has necessitated a simplified calibration procedure for checking their activities. For this purpose and to ease the demand on standard samples of radioactive substances, the National Physical Laboratory's Advisory Committee on Radioactive Standards and 